\title{
The Dawning of a New Age of Toxicology
}

\author{
Marcel Leist ${ }^{1,2}$, Thomas Hartung ${ }^{2}$ and Pierluigi Nicotera ${ }^{3}$ \\ ${ }^{1}$ Doerenkamp-Zbinden Chair for alternative in vitro methods, University of Konstanz, Germany; ${ }^{2}$ ECVAM/ IHCP, EC-Joint \\ Research Centre, Ispra, Italy; ${ }^{3}$ MRC Toxicology Unit, University of Leicester, Leicester, U.K.
}

\section{Summary}

Toxicology faces enormous challenges in a world in which we are exposed to thousands of chemicals and millions of mixtures thereof. Radically new approaches to this problem need to be developed. A milestone in this direction is the vision of the US National Research Council (NRC) "Toxicity testing in the $21^{\text {st }}$ century: a Vision and a Strategy". Currently, an alliance formed by the National Toxicology Program (NTP) and the Chemical Genomics Centre (NCGC) of the National Institutes of Health (NIH) and the Computational Toxicology Centre (NCCT) of the Environmental Protection Agency (EPA) is testing whether this new strategy can realistically form the basis of future public health decisions. The vision requires a radical paradigm shift in the approach to safety assessments, and turns the traditional procedures upside down. Where animal experiments used to be the most important technology, the future is seen in the strength of in vitro and in silico approaches based on human material. Today's toxicity testing starts with an initial black box screen on animals, sometimes followed by mechanistic studies, while the new vision approaches hazard assessment bottom-up. The procedure would begin with in vitro tests to define the affected pathways. To fill remaining gaps of knowledge, limited and targeted testing in animals would then be performed as a possible second step. This means nothing less than changing toxicology from being a predominantly observational craft and regulatory support discipline back to a natural science with all its dimensions. The background and the implications are discussed here in particular for a readership with interest also in parallel European trends.
Zusammenfassung: Toxikologie im Aufbruch

Die Toxikologie steht in einer Welt, in der wir Tausenden von Chemikalien und Millionen von deren Mischungen ausgesetzt sind, vor enormen Herausforderungen. Als Antwort darauf müssen radikal neue Ansätze entwickelt werden, um die Sicherheit der Bevölkerung zu gewährleisten. Ein Meilenstein in dieser Richtung ist die Vision des Nationalen Forschungsrates der USA „Toxizitätstestung im 21. Jahrhundert: Eine Vision und eine Strategie". Gegenwärtig testet eine Allianz, die zwischen dem NTP* und dem NCGC des NIH sowie dem NCCT der EPA gebildet wurde, ob diese neue Strategie realistischerweise eine Basis für künftige Entscheidungen zum Schutz der öffentlichen Gesundheit sein kann. Die Vision setzt einen Paradigmenwechsel im Ansatz von Sicherheitsevaluationen voraus und stellt die traditionell angewandten Verfahren auf den Kopf. Wo bisher Tierexperimente die wichtigste Technologie waren, setzt die Zukunftsvision auf in vitro und in silico Ansätze, die auf menschlichem Material beruhen. Toxizitätstests beginnen heutzutage relativ blind mit einem Tierexperiment, dem dann nur manchmal mechanistische Studien folgen, während die neu vorgeschlagene Strategie die Sicherheitsevaluation von unten her beginnt: Zunächst würden mit in vitro Tests die durch Giftstoffe gestörten Stoffwechsel- und Regulationswege identifiziert; erst in einem möglichen zweiten Schritt kämen dann begrenzte und streng fokussierte Tierversuche dazu, um eventuell noch offene Wissenslücken zu schließen. Dies bedeutet nicht weniger als eine Umkrempelung der Toxikologie von einer hauptsächlich beschreibenden Tätigkeit und Hilfsdisziplin für Behörden wieder hin zu einer Naturwissenschaft mit all ihren Dimensionen. Der Hintergrund und die Konsequenzen werden hier insbesondere für Leser mit einem Interesse auch an parallelen Europäischen Trends beschrieben.

*Die Abkürzungen sind in der englischen Zusammenfassung ausgeschrieben

Keywords: in vitro toxicology, REACH, toxicity pathways, environmental agents

\section{Introduction}

Toxicology is an exciting discipline that brings together specialists from vastly different areas. A picture (Fig. 1) that springs to mind is one of a body with three souls (= dimensions): As for many other medical dis-ciplines, one important aspect of toxicology is that its procedures and the specific knowledge are applied like a craft. In this first domain, which contains the translational aspects of the science, careful documentation, processoptimisation and routine are of high im- portance. A second focus area is regulatory toxicology at the interface of industry and authorities, involved in setting and meeting guidelines and providing a basis for political decisions and legal requirements concerned with environmental health and consumer safety. The third soul of toxicology is its scientific basis. This area is concerned with the genera- 
tion of new knowledge and is linked to other natural sciences. It appears as if the three souls have lost connection over the past decades and that a large part of toxicology became frozen in time, using and accepting the same old animal models again and again, often without stringent examination of their validity (Hartung, $2008 \mathrm{a}, \mathrm{b})$. In this situation, the overall discipline is strongly driven by the demand for protocols and data for regulatory action. Only few resources remain for generation of fresh, fundamental toxicological knowledge and scientific output. A lot of the remaining scientific progress of toxicology depends strongly on import from other biomedical fields (Lotti and Nicotera, 2002). The consequences are reduced innovation, followed by a loss of attractiveness of the field for talented workers, and finally an inability to meet newly arising challenges.

Such new challenges are for instance the safety evaluation of compound mixtures, of biologics, of nanomaterials, of irradiated or genetically-altered food or of mobile phone radiation. None of them can be tackled adequately by classical animal-based methods. Huge challenges lie also in finding more predictive systems for developmental neurotoxicants (Grandjean and Landrigan, 2006) or nongenotoxic carcinogens (Ashby, 1996; Trosko and Upham, 2005; Williams and Whysner, 1996). However, these current problems are also a huge opportunity for the future, to bring the domains of toxicology together again, to link the field more closely to progress in other areas of biomedical sciences, and to give it a new basis (Fig. 1).

There is a vast body of evidence from mechanistic toxicology studies suggesting that the thousands of known noxious substances act by interfering with only a few (i.e. dozens) regulatory pathways of cells (NRC, 2007). For instance, a variety of hepatotoxins act by enhancing TNF-induced apoptosis (Leist et al., 1997), various compounds are neurotoxic because of perturbed cellular calcium metabolism (Nicotera, 1996; Orrenius et al., 2003; Leist and Nicotera, 1998), various immunotoxicants affect the cell cycle of lymphocytes via the Ah receptor (Kolluri, 1999), endocrine disrupters often bind to steroid receptors (Vedani

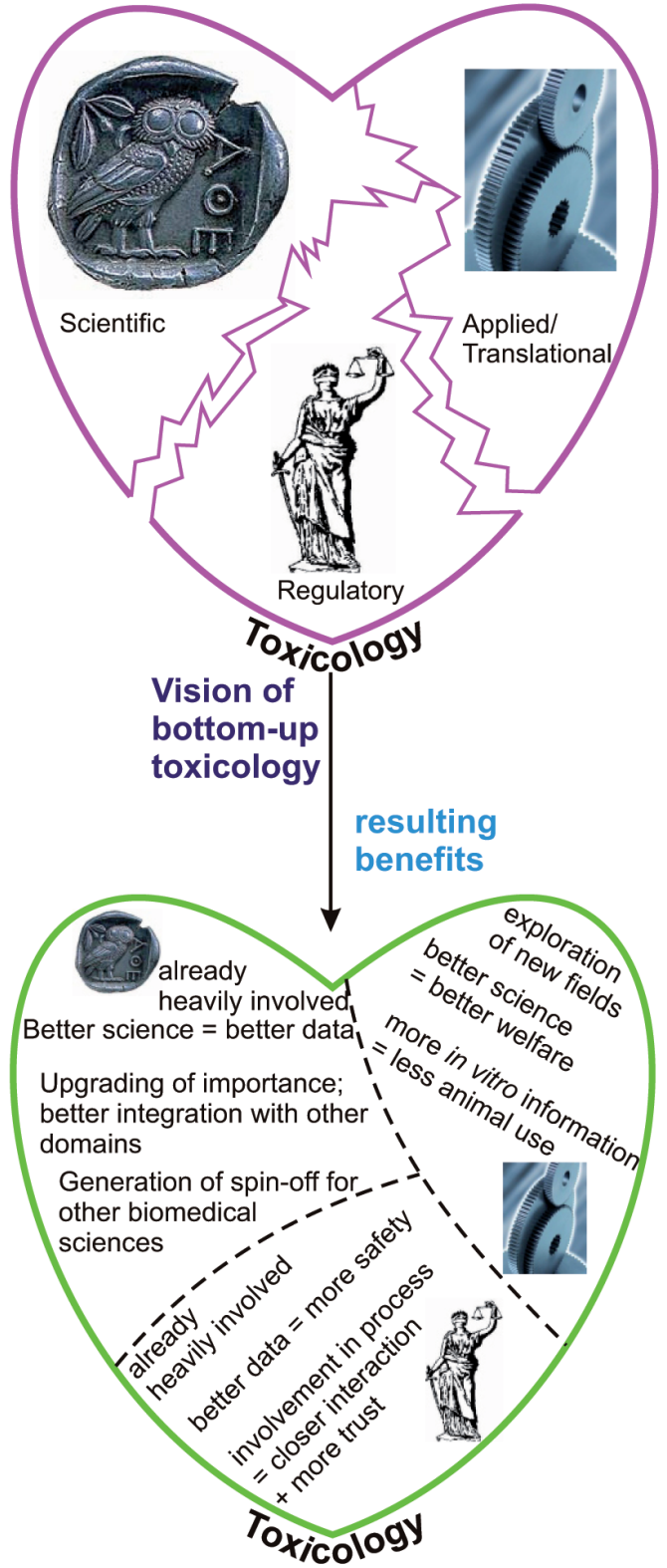

Fig. 1: Good prospects for heartbroken toxicology

Top: The three sou s of tox co ogy (sc ent fic, app ed, regu atory) are not opt ma y connected and the $d s c p$ ne $s$ suffer ng. Dec ded y fo ow ng the $v s$ on for tox $c$ ty test ng $\mathrm{n}$ the $21^{\text {st }}$ century, presented by the Nat ona Research Counc (NRC, USA), tox co ogy can $\mathrm{pu}$ together the $\mathrm{d} s \mathrm{p} p$ nes, strengthen each of them and put safety assessment on a new bas $\mathrm{s} w$ th ess requ rement for an ma exper mentat on.

et al., 2005, 2007; Waring and Harris, 2005), and interaction with the P450 system has been extensively examined as the basis of the toxicity of thousands of diverse compounds (Krebsfaenger et al., 2003; Nussler et al., 2001; Ioannides and Lewis, 2004). Information on such affected pathways can nowadays be obtained rapidly by high-throughput screening systems using human cells, and then be further analysed with modern methods of systems biology and bioinformatics. 
Such a new approach has recently been suggested by the US National Toxicology Roadmap "A national toxicology program for the $21^{\text {st }}$ century" (http://ntp. niehs.nih.gov/files/NTPrdmp.pdf) and the NRC (NRC, 2007), and testing of its feasibility by major safety authorities has begun (Collins et al., 2008).

\section{A new vision of toxicity testing}

The NRC, the most prestigious scientific council of the USA, was funded some years ago by the EPA and the NTP to develop a long range vision and implementation strategy for modern toxicology (Fig. 2; see Box 1 for explanation of the abbreviations). The heart of the new vision of toxicity testing proposed by the NRC is the concept of "toxicity pathways" (Fig. 3). As shown in Figure 3a, the vision takes its starting point from the presumption that most toxicants will eventually act by interfering with pivotal cellular structures and regulatory pathways. This would result in a limited number of toxicity pathways (e.g. disturbed calcium regulation, triggering of apoptosis, cell cycle derangement, ...). It is then further presumed that knowledge of these pathways and knowledge of the action of toxicants on these pathways would allow predictions of toxicity on the level of the whole organism. This is a simple concept, but with huge implications. The practical consequence for toxicity testing would be no less than a turn-around of the currently used process from top to bottom (Fig. 3b, Fig. 4). Currently, animal models are frequently used as black box system to identify problematic compounds. Only in few cases (e.g. for valuable compounds, or compounds leading to high human exposure) will toxicity data ever be followed up to understand why a compound is toxic and whether the effect is relevant to humans. The vision laid out by the NRC suggests a radical paradigm shift. The start of a safety evaluation would begin with the chemical properties of a compound and then proceed to the biological characterisation in multiple in vitro systems (Fig. 3). Bioinformatic procedures would transform this information into a hazard estimate. This procedure would prioritise a few compounds (e.g. unclear hazard estimate or biokinetic predictions and high exposure) for further animal testing, and be sufficient on its own to eliminate many compounds and mixtures.

This would be a revolutionary approach if it was actually applied in practice, but is the idea really new? There is a saying that "success and good news have many parents, uncles, godfathers...., once they are apparent to everybody, while failure is

\section{Box 1: Glossary of terms and abbreviations}

(Q)SAR: (quant tat ve) structure-act v ty re at onsh p. A way to corre ate chem ca structura nformat on $w$ th b o og ca endpo nts (e.g. receptor b nd ng or tox c ty).

ASAT: EU $n t$ at ve on "assurng safety w thout an ma test ng"; http://www.asat- $n t$ at ve.eu

CEFIC: European Chem ca Industry Counc

DG RESEARCH: D rectorate Genera of the EU for research (http://ec.europa.eu/dgs/research/ndex en.htm ). In nat ona terms th $\mathrm{s}$ wou d correspond to the $\mathrm{M} n$ stry for Research. It $\mathrm{s}$ the major fund ng body for the arge EU framework programme research projects.

ECVAM: European Centre for the Va dat on of A ternat ve Methods (http://www.ecvam.jrc. t)

EPA: Env ronmenta Protect on Agency (of the USA)

EPAA: European Partnersh $p$ (of the European Comm ss on and ndustry organ sat ons) for A ternat ve Approaches to An ma Test ng InViTech: the EU h gh-throughput-h gh content centre; http:// bms.jrc.ec.europa.eu/projects/InV Tech.htm

MEIC: In 1989, Björn Ekwa and the Scand nav an Soc ety for Ce Tox co ogy organ sed the Mu t centre Eva uat on of In V tro Cytotox c ty (MEIC). F fty compounds were eva uated $n$ dozens of cytotox c ty assays and the resu ts were pub shed $n$ a ser es of papers n 1998 n ATLA.

MRC: Med ca Research Counc of the UK; runs own research nst tutes, e.g. MRC Tox co ogy Un $\mathrm{n}$ Le cester

NCBI: Nat ona Center for B otechno ogy Informat on, a d v s on of the Nat ona L brary of Med c ne (NLM) at the NIH NCCT: Nat ona Center for Computat ona Tox co ogy (of the USA)
NCGC: NIH Chem ca Genom cs Centre

NIH: Nat ona Inst tutes of Hea th (of the USA)

NRC: Nat ona Research Counc (of the USA), the pr nc pa operat ng agency of the Nat ona Academ es of Sc ences of the USA, the Nat ona Academy of Eng neer ng and the Inst tute of Med $c$ ne. The Nat ona Academy of Sc ences s known by many as pub sher of the Proceed ngs of the Nat ona Academy of Sc ences, USA.

NTC: The Nether ands Tox cogenom cs Centre; http:// tox cogenom cs.n

NTP: Nat ona Tox co ogy Program (of the USA)

PubChem: PubChem prov des nformat on on the $b$ o og ca act $v$ t es of sma mo ecu es. It $s$ a component of the NIH s Mo ecu ar L brar es Roadmap In $t$ at ve.

PubMed: B omed ca terature database at the NCBI

qHTS: quant tat ve $\mathrm{h}$ gh throughput screen ng. Th s techno ogy a ows the test ng of thousands to ten-thousands of compounds $\mathrm{n}$ a s ng e exper ment. Th s compound number s 1-2 orders of magn tude ower than what wou $d$ be used $n$ ndustr a drug $\mathrm{d}$ scovery screens. However, the data output $s$ re at ve y $r$ ch, as compounds are screened at about $10 \mathrm{~d}$ fferent concentrat ons and the shape of the resu tant response curves y e ds add t ona nformat on.

REACH: European regu at on (EC) No 1907/2006 on the Reg strat on, Eva uat on, Author sat on and Restr ct on of Chem ca s, wh ch entered nto force on the $1^{\text {st }}$ of June 2007. ZEBET: Zentra ste e zur Erfassung und Bewertung von Ersatzund Ergänzungsmethoden zum T erversuch am BfR/ Centre for Documentat on and Eva uat on of A ternat ves to An ma Exper ments at the BfR (Federa Inst tute for R sk Assessment) 


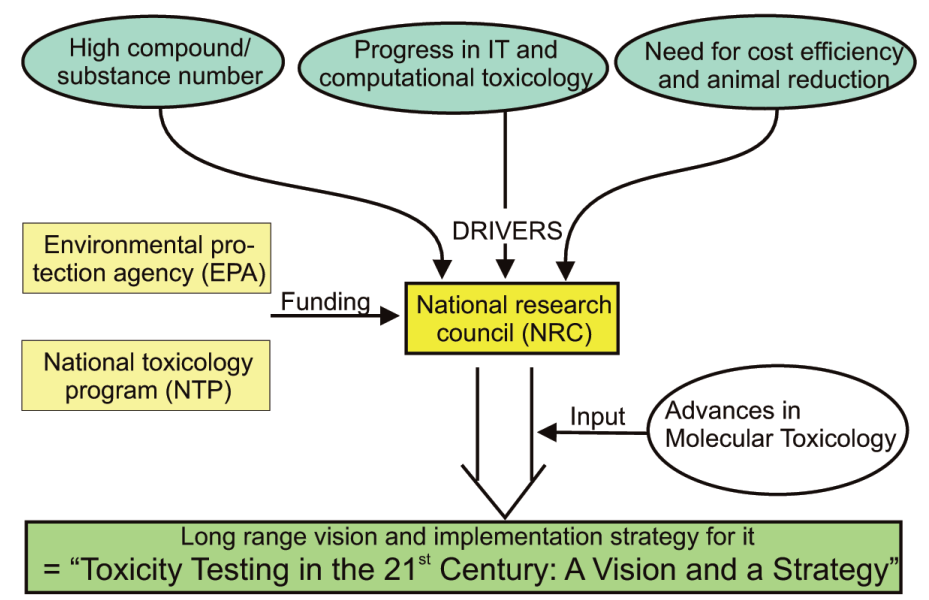

A

\section{Key Questions:}

Which pathway(s)?

Which pathway interactions?

Link of pathway(s) and adverse effect?

Exposure timing?

Chronicity effects?

Particular effects on life stages?

Low dose (additive) effects?

Human variability modelling?
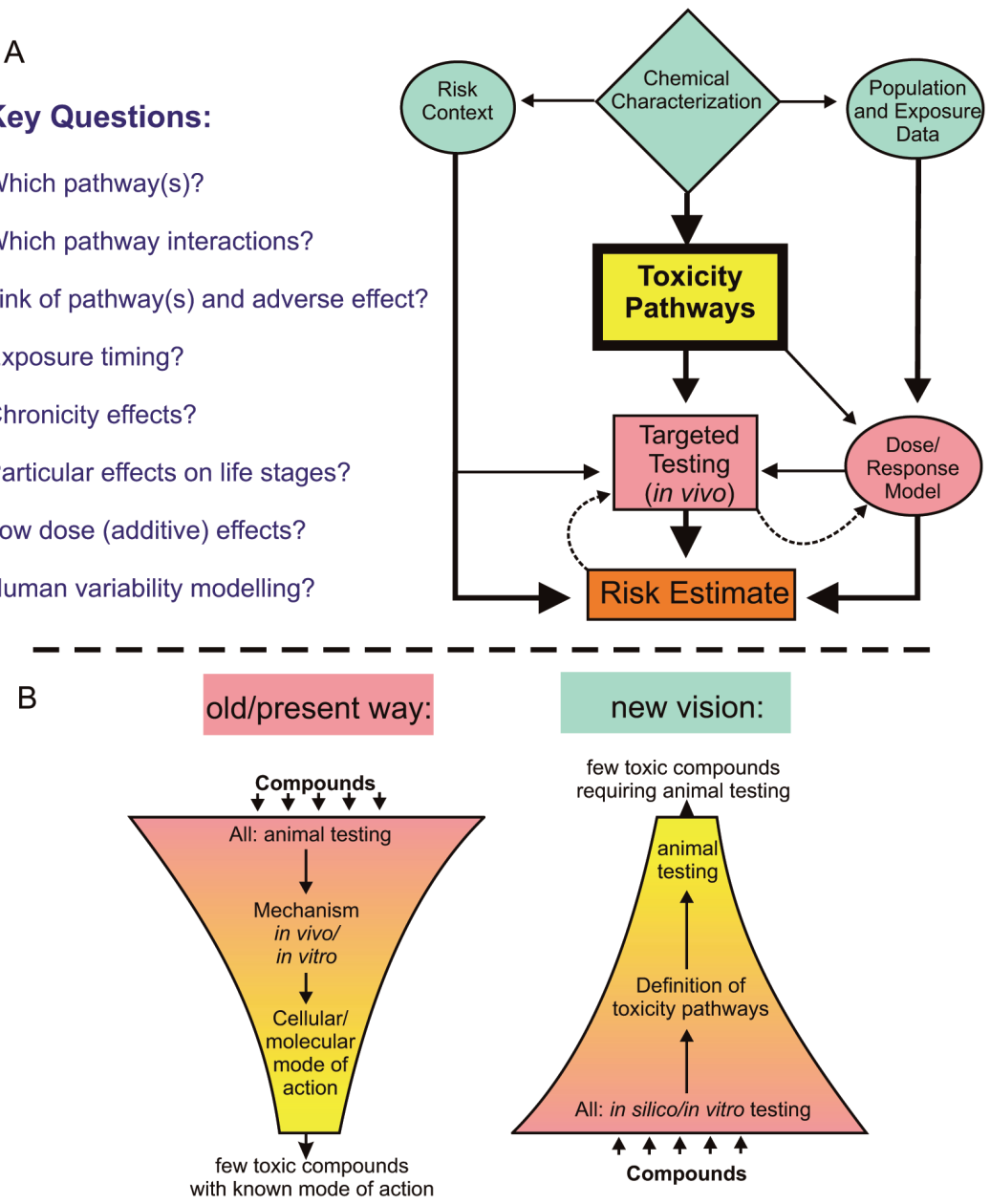

with known mode of action
Fig. 2: Parents and godfathers of the vision

At the end of 2007, the NRC pub shed ts report after the $\mathrm{nta}$ tr gger by two mportant regu atory agenc es a coup e of years ear er. A p vota strength of the procedure, compared to $\mathrm{s} \mathrm{m}$ ar approaches, $s$ the ear $y$ nvo vement of and support by major stakeho ders (academ a, regu ators, ndustry) and the coup ng of a $v s$ on to an mp ementat on strategy.

Fig. 3: Approach to toxicity testing suggested by the NRC (USA)

A. Tox c ty pathways e at the heart of the approach of hazard eva uat on and are exam ned $w$ th the he $p$ of in vitro mode $s$. Gaps of know edge and uncerta nt es are addressed by targeted an ma test ng. R sk est mates are then based on the hazard eva uat on, exposure data and the $r \mathrm{sk}$ context. For eva uat on of th s approach, a number of mportant quest ons need to be addressed. $B$. The new $v$ s on fo ows a bottom-up approach $\mathrm{n}$ contrast to the present approach.

an orphan, with an ugly mother-in-law, at best". Accordingly, many will claim now, that they have worked on the same idea as promoted by the NRC (NRC, 2007) for years, or even decades. It is indeed true that in vitro toxicology is a firmly established and well-organised discipline which has produced similar ideas and also already some applications in the regulatory field and in applied research (Andersen et al., 2005; Hendriksen, 2006; Gruber and Hartung, 2004; Hartung, 2001; Seiler et al., 2006; Whitlow et al., 2007). There has been a continuously good output over decades from laboratories interested in mechanistic toxicology, 


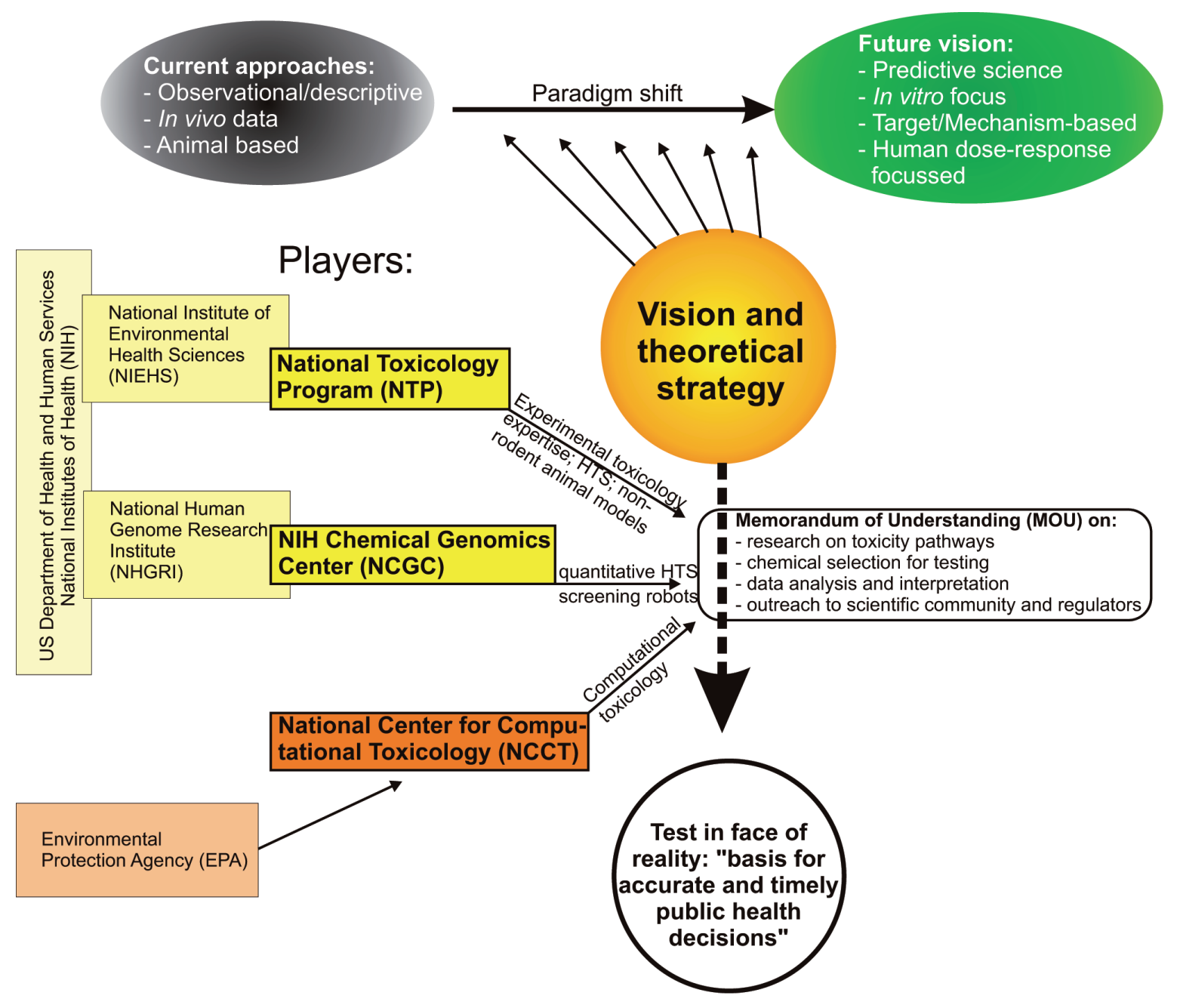

Fig. 4: Testing the feasibility of a new way of toxicity testing and reduction to practice

The $v$ s on and theoret ca strategy were a d down by the NRC. Top: the parad gm sh ft accord ng to th $s$ s on $s$ out ned. Centre + bottom: In order to test whether the $v s$ on ho ds $n$ the face of rea ty three major $p$ ayers agreed $n$ a memorandum of understand $n g$ on a common strategy. The three $p$ ayers are nst tutes and programs of the EPA and the $\mathrm{NIH}$, and contr bute expert se as nd cated.

and many companies and regulatory toxicologists are deeply involved in the development of alternative methods, such as in silico and in vitro screens. For instance, Gerhard Zbinden showed already 20 years ago the trend towards mechanistic models and the necessity for international regulators to follow this line and incorporate the ideas into the regulatory context (Zbinden, 1988, 1990). So again: what's new? It is the way it is done. The determination to "think big", the broad basis, the wide scope, the involvement of many stakeholders and drive by major authorities, the generation of open interfaces to the interested public (including accessible data bases) and the coupling of the vision to an implementation strategy that is robust enough to have a chance for success.

\section{Testing the vision}

A condensed overview of the initial phases of the implementation strategy was given recently by the involved US authorities (Collins et al., 2008). Here, we want to outline the essential features (Fig. 4), mainly as stimulation for the interested European readers and to provide a basis for potential interactions.
Presently, the implementation strategy is being explored by three major players on the basis of a memorandum of understanding clarifying the roles and duties (Fig. 3). One of the contributing institutions is the NCCT (Kavlock et al., 2007) under the roof of the EPA. The two other players are funded by the NIH: The NCGC contributes its screening infrastructure (robots, compound management, high-throughput measurement devices) and performs quantitative high-throughput screens (qHTS). The final player is the NTP which contributes with classical toxicological expertise, non-rodent animal models (for instance 


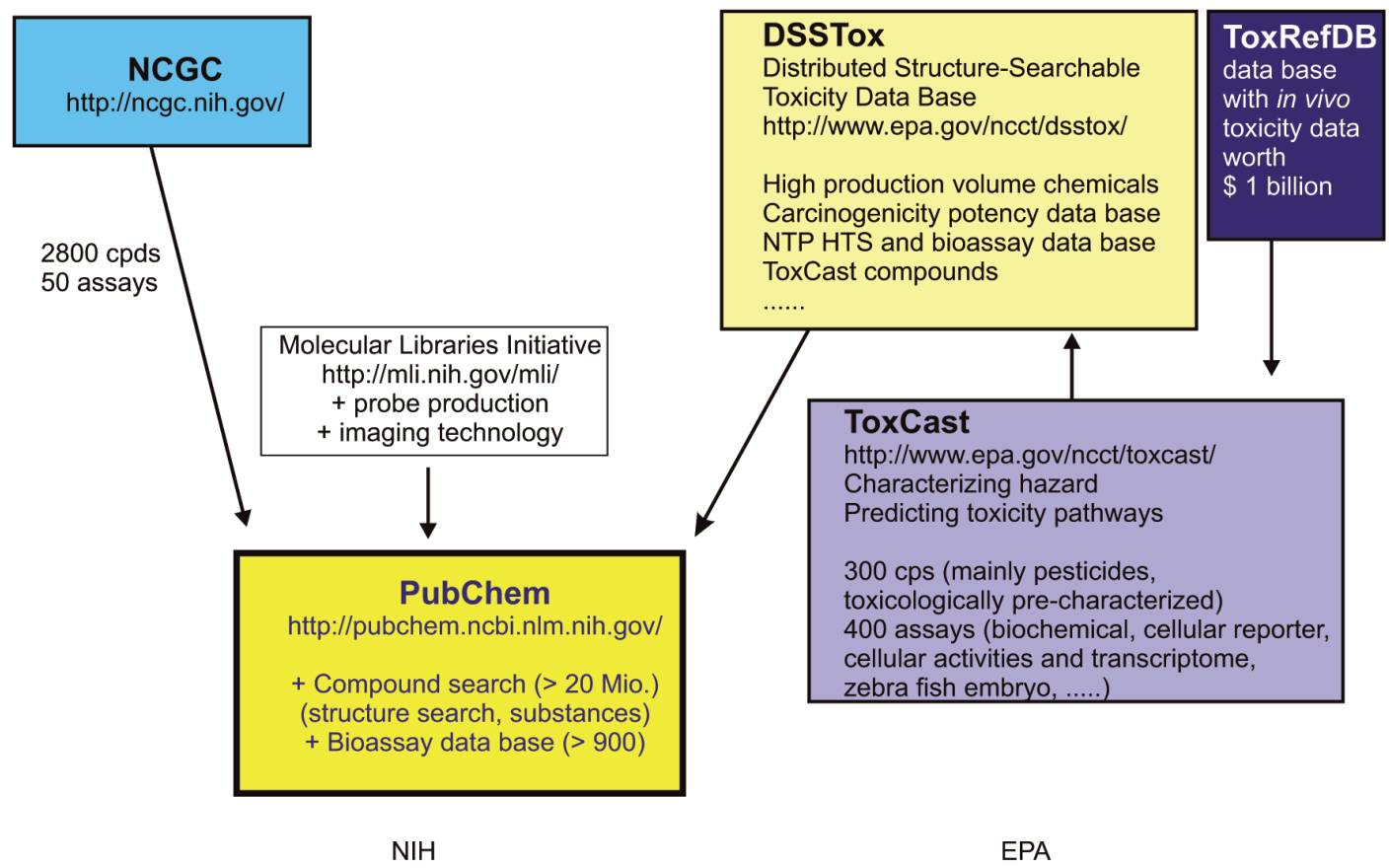

Fig. 5: Databases to help computational toxicology and in vitro toxicity testing

D fferent nter nked databases a ow pub c access to cpd (compound) and assay nformat on. RefToxDB s present y not pub $c y$ access $b$ e. $L$ nks to the other databases are nd cated.

zebra fish embryos) and especially a screen programme for about 300 selected compounds run through hundreds of assays (Fig. 4).

\section{Steps toward a new toxicology}

What happens with the data obtained? Here the idea of open public interfaces and generally-accessible databases comes into play. This sounds like a relatively trivial issue, but it should by no means be underestimated. We all have witnessed how the free internet availability of literature references via NCBI's PubMed has revolutionised the way scientific information is retrieved, and how Google has entirely changed the way general information is retrieved.

Toxicology urgently needs a parallel effort. At present a number of interconnected databases is being developed (Fig. 5) and expanded, but their user-friendliness is far from perfect. Much of the screening data will eventually end up in PubChem, which already harbours over 900 bioassays and will be fed directly with data from screens of the NCGC. Some of this data will also appear in classical journal publications, but in order to understand such publications one will have to be able to retrieve information from PubChem. An example is a publication describing the test of the cytotoxicity of about 1,400 compounds on 13 different cell lines (Xia et al., 2008a). The publication compiles data from different screens and extracts information from comparisons of cell lines and compounds. However, the compounds themselves and the original data from the screens will have to be extracted from the database (Xia et al., 2008b) - and, conversely, the database information may eventually be used again for new analyses and journal publications.

DSSTox is another database with generally richer data sets than PubChem. Here, reviewed and quality-controlled classical toxicological information is added to the compounds. The DSSTox website provides a public forum for publishing downloadable, structure-searchable, standardised chemical structure files associated with toxicity data (Houck et al., 2008).

One important input for DSSTox is Tox-
Cast (Dix et al., 2007). This programme was designed to predict toxicity pathways and to characterise the hazard of a relatively small learning set of tool compounds $(n=300)$ run through 400 different assays. ToxCast $^{\mathrm{TM}}$ signatures will be evaluated by their ability to predict outcomes from existing mammalian toxicity testing and to identify toxicity pathways that are relevant to human health effects. High added value will be generated when this is linked to ToxRefDB, a database designed to contain data from huge historical animal testing efforts, including compounds selected for ToxCast. ToxRefDB is integrated into a more comprehensive data management system developed by NCCT called ACToR (Aggregated Computational Toxicology Resource) that manages the large-scale datasets of ToxCast ${ }^{\mathrm{TM}}$.

The above databases are mainly compound and assay focussed. For hazard assessment further dimensions are essential. We need to understand how the human body handles a given chemical, what the important toxicity pathways are, and how we deal with human genetic variability (Fig. 6). 


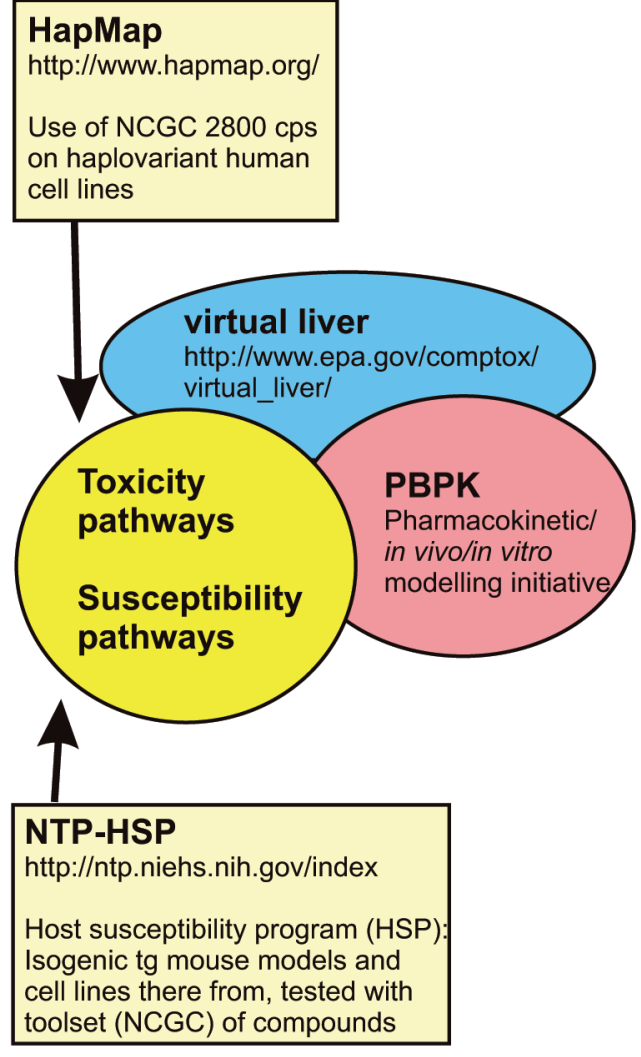

Fig. 6: Identification of toxicity pathways and in vitro-in vivo extrapolation To support the overa project to test a new $\mathrm{v} s$ on for tox $\mathrm{c}$ ty test $\mathrm{ng}$, compound nformat on a one s not suffic ent. An mportant accessory programme $s$ the $n t$ at ve to mode pharmacok net cs and in vitro-in vivo extrapo at ons and dose-response re at onsh ps $w$ th the he $p$ of phys o ogy-based pharmacok net $c$ mode $n g$ (PBPK). Another $\mathrm{n} t$ at ve makes use of the HapMap project. Th s $s$ a mu $t$-country effort to dent fy and cata ogue genet c s $m$ ar t es and d fferences $n$ human be ngs. Us ng th s nformat on, researchers $w$ be ab e to find genes that affect hea th and nd $v$ dua responses to env ronmenta factors. The too brary used by the NCGC (about 2,800 compounds (cps) $w$ be screened on ce nes $w$ th known hap otypes (.e. known genet $c$ var at on). These compounds $w$ a so be tested $w$ th $n$ the HSP on transgen $c(t g) m ~ c e$ and ce $s$ der ved from them. Th $s$ s expected to y e d nformat on on wh ch genes have a major mpact on adverse effects of env ronmenta agents. The b o og ca approach $\mathrm{s}$ comp emented by the $\mathrm{V}$ rtua $\mathrm{L}$ ver Project, wh ch $\mathrm{p}$ ans to deve op a database and a gor thms ab e to pred ct ver tox $c$ ty and forms of ver carc nogen $\mathrm{c}$ ty.

An in vitro test strategy requires more than the test system and data analysis. It cannot function without a prediction model to make use of the data. This also applies to complex integrated test strategies, and here pharmacokinetic information and dose-response modelling become highly important issues for the construction of prediction models. During establishment of the test strategy, variations of the following problem are frequently en-

countered: "pesticide $\mathrm{X}$ induces signs trations, when in vivo doses are given?'
Databases that translate such information are urgently required. During the application of an established test strategy to unknown compounds, a related problem occurs: "compound A triggers toxicity in vitro at concentrations higher than $\mathrm{B}$ micromolar. How much of the compound can be ingested safely?" PBPK databases will need to contain all the essential data on metabolism, protein binding and barrier permeation of compounds, in addition to suitable algorithms that will allow at least rough conversions of in vitro concentrations to in vivo doses. The setup of these databases is still in a very early phase.

The HapMap project is attempting to map and understand human haplotypes (i.e. variants of a given gene that are found in different proportions of the population). This project can also be linked to toxicity testing strategies. Interesting information is expected from testing a set of 2,800 compounds on human cell-lines with known haplovariants. In a parallel approach taken by the host susceptibility program (HSP), compounds are compared through a large number of transgenic mouse models and derived cell lines. These two programmes can contribute to the clarification of toxicity pathways and susceptibility genes and their respective effects. A different approach is taken by the EPA with the VirtualLiver project, which attempts to model the most important target organ of toxicity in its interaction with compounds. On its website it is stated ambitiously that "....the 5-year plan for the Virtual Liver Project is to develop a knowledgebase for qualitatively describing species-specific toxicity pathways due to exposure to chemicals, and to develop a virtual liver tissue that lays the foundation for quantitatively predicting the risk of non-genotoxic neoplastic lesions due to activation of certain genetic regulatory elements (i.e., nuclear receptors and other transcription factors) in humans". toxicity (e.g. muscle paralysis) at a dose of Y mg/kg. Which concentrations should induce a positive readout in a corresponding in vitro toxicity test system in order to consider the test system relevant. In other words, which in vitro cytotoxic concentration would one predict from the in vivo data? Which would be a biologically relevant prediction model for in vitro concen-

\section{The precautionary principle}

Toxicological studies are designed to provide a basis for consumer protection by identifying hazardous compounds. The test systems will necessarily also produce false positives (compounds that are not hazardous to humans, but look hazardous in the 
test system) and false negatives (compounds that are hazardous to humans, but are not correctly identified by the test system) (Leist et al., 2008). The latter class has been of particular concern. Therefore, the test systems and prediction models were tuned in a way to minimise this class as far as possible at cost of a largely increased class of false positives. This tuning of toxicity testing is called the precautionary principle and is one of the corner stones of toxicological thinking. Major changes in toxicity testing will always provoke fears in the public, in regulatory authorities and in other stakeholders that the precautionary principle may be violated. Therefore one of the major tasks of the implementation strategy of a new vision is to address these worries and to generate confidence that the safety level will not be compromised.

A first important issue to be considered is the understanding of the concept of "applicability domains". All toxicological methods are not generally applicable, but have applicability domains, i.e. limitations as to for which part of the chemical universe their predictive value has been shown. For instance, "drugs" or "pesticides" are typical applicability domains. Test guidelines, legislation, authorities, and the questions asked are vastly different in these areas. Other applicability domains would be industrial chemicals, cosmetics, biologics, and food additives. The concept was taken from the field of (Q)SAR and translated to test methods first in ECVAM's Modular Approach (Hartung et al., 2004). The vision discussed here applies mainly to the domain of environmental agents (i.e. pesticides or chemicals with relevant human exposure, for instance through the food chain). This is also reflected by different risk context scenarios that are explored and that are an important feature of the implementation strategy. Whether it can be translated to other domains without compromising the precautionary principle is one of the open questions for the future, and will certainly involve additional stakeholders.

The key issue to consider is, what new methods of toxicity testing should be used for comparison? Can we expect a $100 \%$ failsafe method? We know that present animal-based testing does not guarantee absolute safety (Zbinden, 1991). This is an obvious fact that is often forgotten in discussions on new approaches. New alternative tests are validated stringently (Hartung, 2007a), while many animal tests have never been formally validated (Hartung, 2008a,b). Even studies that address the question whether animal studies are of any toxicological use at all with respect to human safety are extremely scarce (Mathews, 2008). At least some doubt comes from the extreme variation of results when one and the same compound is used in different animal studies, and from the partially poor correlations between one species and the next, for instance between mouse and rat (Hartung, 2008a). Thus, a fair and honest approach to alternative testing strategies would imply that one does not require a $100 \%$ safety level, but rather a safety level that is in the range of (or at least as good as) that of standard animal experimentation. This also implies that showing the one or other insufficiency of in vitro approaches, and of the cell culture technology in particular (Hartung, 2007b), does not invalidate the usefulness of a technology. The strengths and weaknesses of animal and non-animal test approaches will just lie in different areas. Only looking at the comparison of the overall performance with regards to human safety will allow a reasonable judgement of the value.

In this context it is important to reconsider what the ultimate aim of the precautionary principle is: human safety. Sometimes, more exact knowledge on toxicity does not contribute to higher safety, but precautionary measures, e.g. regarding the transport of chemicals, take this function. Extensive animal testing will often generate redundant information, and, in addition, we accumulate more false-positive results (Bremer et al. 2007). To trigger a certain and adequate set of measures, sometimes limited in vitro and in silico information may be sufficient (Rogers et al., 2003).

\section{The European side}

The 3R principle (reduce, replace, refine), which already envisaged a combination of in vitro and in vivo approaches in the 1950's was originally developed in Europe (Russell and Burch, 1959). Is European toxicology less visionary now? What could be learned from the NIH/ EPA approach?
Europe has a different, more diversified, but also more fragmented political landscape and different countries have found their own ways. For instance, the MRC in the UK decided almost 10 years ago to restructure its entire central toxicology institute in Leicester. Already at that time the guiding principle was to promote research on bottom-up toxicology, taking its starting point from understanding toxicity pathways and common processes like apoptosis. In Germany, ZEBET, a federal institution, was established nearly 20 years ago to develop, test and validate alternative methods to animal experimentation, and has been a major driver in the design of the first OECD toxicity testing guidelines based on in vitro testing only (for phototoxicity) and skin corrosion.

On the EU level, the first major driver for a new vision of toxicity testing comes from a different applicability domain than in the US - from cosmetics products. Here, the vision was immediately reduced to practice by law. The $7^{\text {th }}$ amendment of the Cosmetics Directive set a strict timeline, finally banning the use of cosmetics if their ingredients were tested on animals. The implementation strategy implies that industry will need to establish animal-free test methods or change the business model. This is an interesting test case for the whole world to follow. In order to guide the development of methods and to ensure their validity, the EU founded ECVAM in 1992, a research institute entirely devoted to the validation of alternative methods. Now corresponding agencies and institutes are also found in the USA, Japan and other countries (Bottini et al., 2007). ECVAM harbours also an important database, DB-Alm, which is a high-quality source for in vitro test protocols and alternative methods (DB-Alm, 2007).

At present, the major driver for a rethinking of toxicity testing in Europe, is the REACH legislation (REACH, 2006). Over the last two years a revolution of the concept of how safety of chemicals is evaluated took place in Europe in this context: While in the past a (tonnagetriggered) set of mainly animal tests had to be provided in a tick-box manner, now (for both existing and new chemicals) integrated testing strategies making use of all information opportunities must be ap- 
plied. A group of more than 200 experts from regulatory bodies, European Commission and industry developed these strategies (http://ecb.jrc.it/reach/rip/) in REACH Implementation Project 3.3 under the coordination of CEFIC and ECVAM. New and existing approaches were combined in order to optimise information generation for REACH, making use also of in vitro, in silico and read-across data from similar compounds. This law is at the basis of an enormous effort to reevaluate about 30,000 chemicals already marketed in the EU and generates major financial and logistic pressures in addition to the ethical problem of the requirement for millions or tens of millions of animals to fulfil the test requirements. Faced with this enormous challenge, industry and the European Commission formed a partnership in the form of the EPAA (EPAA, 2006), that is working on new visions and implementation strategies. In parallel, the Directorate General of Research (DG Research) is heavily funding research consortia within the sixth and seventh framework programme to develop new in vitro test systems and strategies.

The key feature of REACH in the context of new visions of toxicology is that it has been influenced by an important postulate of the European animal legislation from 1986 (Directive 609/86), which can be summarised as "when alternatives to animal experimentation are available, they must be used"; "more of these alternatives need to be developed". More precisely, article 7.2. states: "An experiment shall not be performed if another scientifically satisfactory method of obtaining the result sought, not entailing the use of an animal, is reasonably and practicably available." And in Article 23.1.: "The Commission and Member States should encourage research into the development and validation of alternative techniques which could provide the same level of information as that obtained in experiments using animals but which involve fewer animals or which entail less painful procedures, and shall take such other steps as they consider appropriate to encourage research in this field."

Article 1.1 of the REACH regulation reads: "Aim and scope 1. The purpose of this regulation is to ensure a high level of protection of human health and the envi- ronment, including the promotion of alternative methods for assessment of hazards of substances, as well as the free circulation of substances on the internal market while enhancing competitiveness and innovation." (our high-lighting). REACH is thus the first major legislation in the huge application domain of industrial chemicals that gives some space for "intelligent test strategies", read-across between different information domains, the use of validated alternative methods, and also the use of non-validated alternative methods at least in a preliminary hazard evaluation (Bremer et al. 2007; Combes et al., 2008; Grindon et al., 2008a,b).

Nevertheless, REACH will still require millions of animal experiments, and the free space given by legislation is still far away from the vision of toxicity testing in the $21^{\text {st }}$ century laid out by the NRC. Whether this heavy animal testing effort will lead to a parallel increase of human safety with respect to chemicals already on the market has been doubted (Knight, 2007). Thus, a new movement is presently forming that focuses on a more stringent validation of animal models and promotes an evidence-based toxicology, in which the best given test strategy is used instead of stringent adherence to only historically-legitimated animal models (Hoffmann and Hartung, 2006; Guzelian et al., 2005; Hartung, 2008b). A multitude of bottom-up movements are emerging at present, which include for instance ASAT, the NTC, and InViTech, to name a few.

\section{Tasks ahead}

We have tried here to survey exciting new developments and movements. Proof-ofconcept studies need to clearly demonstrate the predictive power gained from

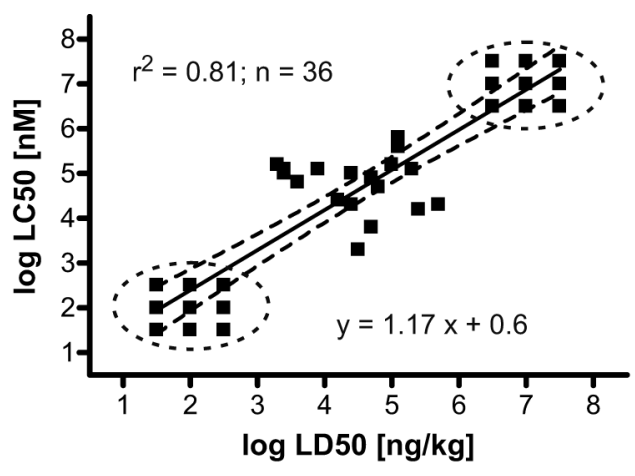

Fig. 7: Selection of libraries for in vitro vs. in vivo correlations

The graph shows an apparent corre at on of in vitro tox $c$ ty data (ha f-max ma effect ve concentrat on $=\mathrm{LC}_{50} \mathrm{nnM}$ ) $\mathrm{w}$ th acute tox $\mathrm{c}$ ty an ma data (ha $\mathrm{f}-\mathrm{max}$ ma etha dose $=$ $\mathrm{LD}_{50} \mathrm{n} \mathrm{ng} / \mathrm{kg}$ ). The examp e shows the danger of obta $\mathrm{n} n \mathrm{ng}$ mean $\mathrm{ng}$ ess corre at ons, when extreme pos $t$ ve and negat ve contro $s$ are chosen (as s common pract ce $n$ the terature), and the number of samp es $\mathrm{n}$ between $\mathrm{s}$ not re at ve $\mathrm{yh}$ gh (as $\mathrm{s}$ a so frequent y observed). A sc ent fic approach $w$ th regards to brary des gn, adm $n$ strat on and va dat on s one essent a prerequ s te for new approaches to tox co ogy. $\mathrm{N}$ ne compounds were se ected as "pos t ve contro s" ( ower c rc e) w th h gh tox c ty, and n ne compounds as "negat ve contro s" w th ow tox c ty (upper c rc e). For eas er dent ficat on on the graph, contro s were chosen w th a comb nat ons of tox c ty of $2 \pm 0.5$ or $7 \pm 0.5$ og $[\mathrm{nM}$ or $\mathrm{ng} / \mathrm{kg}$ ], respect ve $\mathrm{y}$, under the assumpt on that very tox c compounds in vitro $\mathrm{w}$ a so be very tox $c$ in vivo, and that compounds of very ow tox c ty w show that ow effect $\mathrm{n}$ both systems. Further, 18 compounds were random y ass gned a tox $\mathrm{c}$ ty on a sca $\mathrm{e}$ of $3-6$ ( .e. tox $c$ t es $n$ the $m$ dd e range vary $n g$ by a factor of thousand, and $w$ th no corre at on at a of in vitro and in vivo data) by Monte Car o s mu at ons. A representat ve examp e s shown. Under these cond t ons, "apparent y" extreme y good corre at ons are observed ( $\mathrm{r}^{2}=0.8$ and $\mathrm{h}$ gher). Corre at ons rema $\mathrm{n}$ st reasonab y good (range of 0.52 0.61 ), when the number of compounds $w$ th random propert es $s$ doub ed to 36 . 
these new approaches. More researchers need to be attracted to join the efforts, and regulatory authorities must show a willingness to embrace the new approaches as they gain scientific acceptance. The next few years should witness the early fruits of such efforts, but the paradigm shift will require a long-term investment and commitment to reach full potential. In a brief last paragraph we want to summarise critical issues to be addressed by the scientific community, granting agencies and authorities (Fig. 8):

Databases: These require a change of attitude as they move more into the centre of the process instead of being a final end product. It often appears from the lack of care and the limited analysis and accessibility options that they are more or less considered a tiresome duty to those who have generated the data. It is not sufficient to simply "dump" the data somewhere, even if they are flexibly retrievable and adequately quality-controlled. The science of visualisation of data and especially visualisation of large complex data spaces needs to be applied much more strongly here. The importance of this process and the need for users and developers to hold a constant dialogue during the design of analysis and visualisation algorithms are still heavily underestimated. Another important issue is the cross-linking of information. For instance a number of databases have been generated in Europe on in vitro acute toxicity data. For instance the MEIC data base (see Box 1) covers a very large number of toxicity assays, and the Halle Registry (Halle, 2003) over 300 in vitro-in vivo comparisons, but cross-linking is limited, as is the general and easy accessibility.

Libraries: To fill the databases with information, real compounds are required. Especially in the proof-of-principle phase of testing, the selection of these compound libraries plays an important role (Fig. 7) and contributes to the success, the validity and the general acceptance of validation efforts. Not only will the right "theoretical" composition of the libraries be of high importance, but also the physical composition and availability. Compound stability and purity, the general accessibility and continuous quality control are non-trivial issues, especially in the field of environmental chemicals,

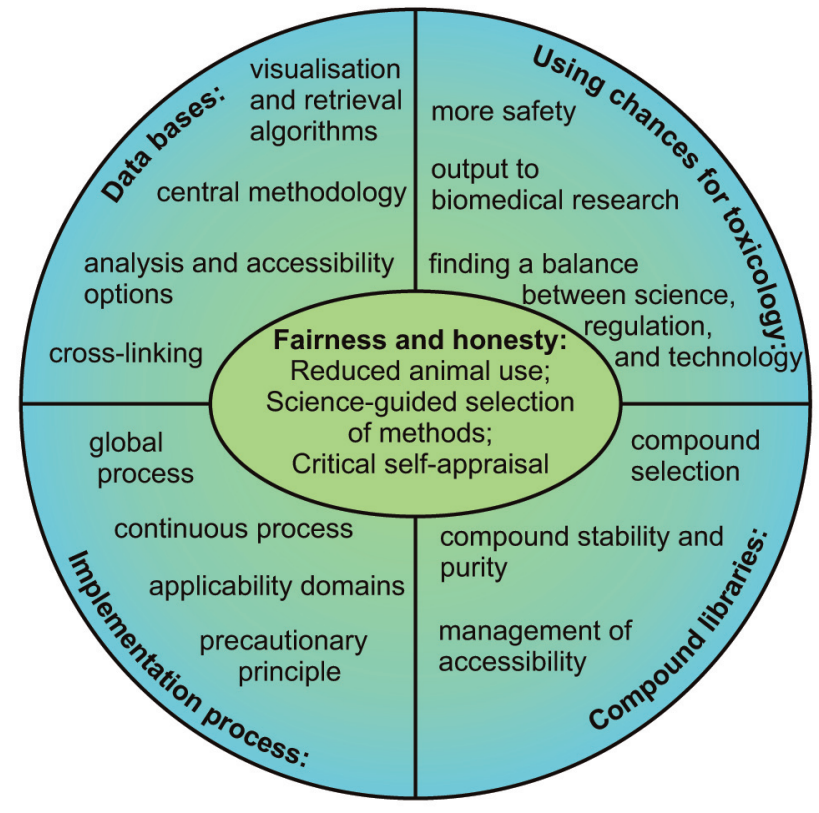

Fig. 8: Compilation of tasks ahead and associated key issues

industrial chemicals and pesticides. Here one solution to be considered is chemical reference laboratories making defined library copies available to others. This has been conceptualised on the European level in form of CORRELATE (Correlate, 2007) and should also be considered as a great opportunity in the context of REACH (see Hartung, 2008b).

Process: Many areas of basic biomedical research have experienced bumpy rides with periods of hype and disappointment. Toxicology has a continuous high responsibility for human safety and cannot, even transiently, simply drop the precautionary principle. However, it can ask critical questions on how it should best be applied in different situations, exposure scenarios and applicability domains. This provides a basis for a continuous, long-term effort to let toxicology evolve to a higher level than now. This process needs essentially to be global and involve all stakeholders (Bottini et al., 2007). Despite all enthusiasm, rapid success is not to be expected and all hype had rather be avoided as initial setbacks are likely to happen. This has to be accepted in the strategy. However, the determination to move on needs to be strong enough to attack problems with the right critical mass and impact right from the beginning and as they emerge.
Chances: The process of putting regulatory toxicology and the process of toxicity testing on a more mechanistic basis provides a chance for toxicology to evolve as a discipline, and also contribute general biomedical knowledge. This closes the circle started at the beginning of this article (Fig. 1). In the past, toxicology had the chance to promote the advance of biomedical sciences in general, for instance by discovering and driving the fields of apoptosis, toxinology or stress response. However, these opportunities were not seized, and other sciences drove these fields instead. Now, new chances are arising, possibly in the fields of systems biology, DNA repair or pathological aging. Possibly, also in the fields of chemical genetics and the introduction of chemical screens to non-pharmaceutical areas. To grasp any of these chances, it is important to dare to take the lead and not to lose touch with basic science. Application of HTS or qHTS as described above sounds fancy, but it is at the moment only a technology, not a science. This technology has brought a lot of disappointment in drug discovery, which one can learn from. It will be important in the future to avoid the mistakes of the past, and to incorporate the "technology" into a robust "scientific concept", which combines brain with the muscles. 
Fairness and honesty: An unbiased approach, based on scientific evidence only, will be the best way to find solutions acceptable for all stakeholders. Presently one may wonder what the scientific basis for some animal experiments is. The lousy output and poor information from acute toxicity studies with lethality endpoint has been criticised for a long time (Tamborini et al., 1990; Zbinden, 1986; Paget, 1983; Zbinden and Flury-Roversi, 1981), and now, at least in the application domain of drugs, there seems to be a broad agreement that the assay could easily have been abolished (Robinson et al., 2007). Why hasn't this already happened? A similar situation can be found for two-generation studies for developmental toxicity testing, where the second generation apparently does not contribute with significant information (Janer et al., 2007). Here, non-scientific reasons seem to prevail, and the argument may be expanded to more examples of animal toxicity testing (Hartung, 2008a). It is also a sign of poor science that so little pharmacokinetic information is available from acute toxicity tests. This makes the present in vivo-in vitro comparisons very difficult and thus prevents a potential substitution of animal experiments by alternative methods. To be honest, the field of alternative methods also needs to look at obvious weaknesses of its own methods and establish itself as an academic discipline (Leist, 2006). Many assays are still just as much black box systems as animal experiments and pharmacokinetic information has been terribly neglected. If all sides focus on a vision of best science for best toxicology, then the sun will indeed rise on a new era.

\section{References}

Andersen, M.E., Dennison, J.E., Thomas, R. S. and Conolly, R. B. (2005). New directions in incidence-dose modeling. Trends Biotechnol. 23(3), 122-127.

Ashby, J. (1996). Alternatives to the 2-species bioassay for the identification of potential human carcinogens. Hum. Exp. Toxicol. 15, 183-202.

Bottini, A. A., Amcoff, P., Hartung, T. (2007). Food for thought ... on globalization. ALTEX 24, 255-261

Bremer, S., Pellizzer, C., Hoffmann, S. et al. (2007). The development of new concepts for assessing reproductive toxicity applicable to large scale toxicological programmes. Curr. Pharm. Des. 13(29), 3047-3058.

Collins, F. S., Gray, G. M., Bucher, J. R. (2008). Toxicology. Transforming environmental health protection. Science 319, 906-907.

Combes, R., Grindon, C., Cronin, M. T. et al. (2008). Integrated decision-tree testing strategies for acute systemic toxicity and toxicokinetics with respect to the requirements of the EU REACH legislation. ATLA 36(1), 45-63.

Correlate (2007). http://projects-2007.jrc. ec.europa.eu/show.gx?Object.object_ $\mathrm{id}=$ PROJECTS0000000003008C51

DB-Alm (2007). Invittox protocol number 101. http://ecvam-dbalm.jrc.ec.europa. eu/public_view_doc2.cfm?id=6E7E72 104B2DEFD6BE979B3B139176C671 80BB0BC12CB10496CDA74B54630 A05A3291B895581F634

Dix, D. J., Houck, K. A., Martin, M. T. et al. (2007). The ToxCast program for prioritizing toxicity testing of environmental chemicals. Tox. Sci. 95, 5-12.

EPAA (2006). European Partnership to Promote Alternative Approaches to Animal Testing http://ec.europa.eu/enterprise/epaa/conf_2006_presentationvdgraaf_unilever.pdf

Grandjean, P., Landrigan, P. J. (2006). Developmental neurotoxicity of industrial chemicals. Lancet 368, 2167-2178.

Grindon, C., Combes, R., Cronin, M. T. et al. (2008a). An integrated decision-tree testing strategy for repeat dose toxicity with respect to the requirements of the EU REACH legislation. ATLA 36(1), 93-101. PMID: 18333717

Grindon, C., Combes, R., Cronin, M. T. et al. (2008b). Integrated decision-tree testing strategies for developmental and reproductive toxicity with respect to the requirements of the EU REACH legislation. ATLA 36(1), 65-80.

Gruber, F. P., Hartung, T. (2004). Alternatives to animal experimentation in basic research. ALTEX 21 Suppl. 1, 3-31.

Guzelian, P. S., Victoroff, M. S., Halmes, N. C. et al. (2005). Evidence-based toxicology: a comprehensive framework for causation. Hum. Exp. Toxicol. 24, 161-201.

Halle, W. (2003). The Registry of Cytotoxicity: toxicity testing in cell cultures to predict acute toxicity $\left(\mathrm{LD}_{50}\right)$ and to reduce testing in animals. ATLA 31, 89-198.

Hartung, T. (2001). Three Rs potential in the development and quality control of pharmaceuticals. ALTEX 18 Suppl. 1, 3-13.

Hartung, T., Bremer, S., Casati, S. (2004). A Modular Approach to the ECVAM Principles on Test Validity. ATLA 32, 467-472.

Hartung, T. (2007a). Food for thought on .....validation. ALTEX 24, 67-73.

Hartung, T. (2007b). Food for thought on .....cell culture. ALTEX 24, 143-147.

Hartung, T. (2008a). Food for thought.... on animal tests. ALTEX 25, 3-10.

Hartung, T. (2008b). Food for thought..... on the evolution of toxicology and phasing out of animal testing. ALTEX 25, (this issue, page 91).

Hendriksen, C. F. (2006). Towards eliminating the use of animals for regulatory required vaccine quality control. $A L$ TEX 23, 187-190.

Hoffmann, S., Hartung, T. (2006). Toward an evidence-based toxicology. Hum. Exp. Toxicol. 25, 497-513.

Houck, K., Dix, D., Judson, R. et al. (2008). DSSTox EPA ToxCast High Throughput Screening Testing Chemicals Structure-Index File: SDF File and Documentation, Updated version: TOXCST_v2b_320_08Feb2008,http:// www.epa.gov/ncet/dsstox/sdf_toxcst. html

Ioannides, C., Lewis, D. F. (2004). Cytochromes $\mathrm{P} 450$ in the bioactivation of chemicals. Curr. Top. Med. Chem. 4, 1767-1788.

Janer, G., Hakkert, B. C., Slob, W. et al. (2007). A retrospective analysis of the two-generation study: what is the added value of the second generation? Reprod. Toxicol. 24, 97-102.

Kavlock, R. J., Ankley, G., Blancato, J. et al. (2007). Computational Toxicology - A State of the Science Mini Review. ToxSci. Advance Access published on December 7, 2007. doi:10.1093/toxsci/ kfm297

Knight, A. (2007). Animal experiments scrutinised: systematic reviews demonstrate poor human clinical and toxicological utility. ALTEX 24(4), 320-325.

Kolluri, S. K., Weiss, C., Koff, A., Göttlicher, M. (1999). p27(Kip1) induction and inhibition of proliferation by the 
intracellular Ah receptor in developing thymus and hepatoma cells. Genes Dev. 13, 1742-1753.

Krebsfaenger, N., Mürdter, T. E., Zanger, U. M. (2003). V79 Chinese hamster cells genetically engineered for polymorphic cytochrome P450 2D6 and their predictive value for humans. $A L$ TEX 20, 143-154.

Leist, M., Gantner, F., Naumann, H. et al. (1997). Tumor necrosis factor-induced apoptosis during the poisoning of mice with hepatotoxins. Gastroenterology 112, 923-934.

Leist, M, Nicotera, P. (1998). Calcium and neuronal death. Rev. Physiol. Biochem. Pharmacol. 132, 79-125.

Leist, M. (2006). What can a chair on alternatives to animal experimentation effectuate? ALTEX 23, 211-213.

Leist, M., Kadereit, S., Schildknecht, S. (2008). Food for thought.... on the real value of 3R approaches. ALTEX 25, 17 24.

Lotti, M., Nicotera, P. (2002). Toxicology: a risky business. Nature 416, 481 .

Mathews, R. A. J. (2008). Medical progress depends on animal models doesn't it? J. R. Soc. Med. 101, 95-98.

Nagel, R. (2002). DarT: The embryo test with the Zebrafish Danio rerio - a general model in ecotoxicology and toxicology. ALTEX 19 Suppl. 1, 38-48.

Nicotera, P. (1996). The Gerhard Zbinden Memorial Lecture. Alteration of cell signalling in chemical toxicity. Arch. Toxicol. 18 Suppl., 3-11.

NRC (2007). Committee on Toxicity Testing and Assessment of Environmental Agents, National Research Council. Toxicity Testing in the 21st Century: A Vision and a Strategy. The National Academies Press. http://www.nap.edu/ catalog.php?record_id=11970

Nussler, A. K., Wang, A., Neuhaus, P. et al. (2001). The suitability of hepatocyte culture models to study various aspects of drug metabolism. ALTEX 18, 91 101.

Orrenius, S., Zhivotovsky, B., Nicotera, P. (2003). Regulation of cell death: the calcium-apoptosis link. Nat. Rev. Mol. Cell Biol. 4, 552-565.

Paget, E. (1983). The $\mathrm{LD}_{50}$ test. Acta Pharmacol. Toxicol. (Copenh.) 52 Suppl. 2, 6-19.
REACH (2006). REACH legislation under directive (EC) No 1907/2006, http://eur-lex.europa.eu/JOHtml.do?uri $=\mathrm{OJ}: \mathrm{L}: 2006: 396:$ SOM:en:HTML

Robinson, S., Delongeas, J. L., Donald, E. et al. (2007). A European pharmaceutical company initiative challenging the regulatory requirement for acute toxicity studies in pharmaceutical drug development. Regulatory Toxicol. Pharmacol. ( in press). doi:10.1016/j. yrtph.2007.11.009

Rogers, M. D. (2003). Risk analysis under uncertainty, the precautionary principle, and the new EU chemicals strategy. Regul. Toxicol. Pharmacol. 37, 370-381.

Russell, W. M. and Burch, R. L. (1959). The Principles of Humane Experimental Technique. London: Methuen.

Seiler, A., Buesen, R., Hayess, K. et al. (2006). Current status of the embryonic stem cell test: the use of recent advances in the field of stem cell technology and gene expression analysis. ALTEX 23 Suppl., 393-399.

Tamborini, P., Sigg, H., Zbinden, G. (1990). Acute toxicity testing in the nonlethal dose range: a new approach. Regul. Toxicol. Pharmacol. 12, 69-87.

Trosko, J. E., Upham, B. L. (2005). The emperor wears no clothes in the field of carcinogen risk assessment: ignored concepts in cancer risk assessment. Mutagenesis 20, 81-92.

Vedani, A., Dobler, M., Lill, M. A. (2005). Virtual test kits for predicting harmful effects triggered by drugs and chemicals mediated by specific proteins. $A L$ TEX 22, 123-134.

Vedani, A., Dobler, M., Spreafico, M. et al. (2007). VirtualToxLab - in silico prediction of the toxic potential of drugs and environmental chemicals: evaluation status and internet access protocol. ALTEX 24, 153-161.

Waring, R. H., Harris, R. M. (2005). Endocrine disrupters: a human risk? Mol. Cell Endocrinol. 244, 2-9.

Whitlow, S., Bürgin, H., Clemann, N. (2007). The embryonic stem cell test for the early selection of pharmaceutical compounds. ALTEX 24, 3-7.

Williams, G. M., Whysner, J. (1996). Epigenetic carcinogens: evaluation and risk assessment. Exp. Toxicol. Pathol.
48, 189-195.

Xia, M., Huang, R., Witt, K. L. et al. (2008a). Compound cytotoxicity profiling using quantitative high-throughput screening. Environ. Health Perspect. 116, 284-291.

Xia, M. et al. (2008b). The 1408 compounds of Environ Health Perspect 116, 284. http://www.epa.gov/ncct/dsstox/ sdf_ntphts.html\#DownloadTable

Zbinden, G., Flury-Roversi, M. (1981). Significance of the LD50-test for the toxicological evaluation of chemical substances. Arch. Toxicol. 47, 77-99.

Zbinden, G. (1986). Invited contribution: acute toxicity testing, public responsibility and scientific challenges. Cell Biol. Toxicol. 2, 325-335.

Zbinden, G. (1988). Reduction and replacement of laboratory animals in toxicological testing and research. Interim report 1984-1987. Biomed. Environ. Sci. 1, 90-100.

Zbinden, G. (1990). Alternatives to animal experimentation: developing invitro methods and changing legislation. Trends Pharmacol. Sci. 11, 104-107.

Zbinden, G. (1991). Predictive value of animal studies in toxicology. Regul. Toxicol. Pharmacol. 14, 167-177.

\section{Acknowledgement}

We gratefully acknowledge the valuable input and proofreading of Suzanne Kadereit and Stefan Schildknecht, the secretarial help by Brigitte Schanze and grant support by the DoerenkampZbinden Foundation, the State of BadenWürttemberg and the European Union (ESNATS).

\section{Correspondence to:}

Prof. Dr. Marcel Leist

Doerenkamp-Zbinden Chair for alternative in vitro methods

Faculty of Natural Sciences and Mathematics

University of Konstanz

PO Box M657

78457 Konstanz

Germany

e-mail: marcel.leist@uni-konstanz.de

Tel.: +49-7531-885037

Fax: +49-7531-885039 